\title{
Modelos de geração e variabilidade no volume diário de veículos em shopping centers
}

\author{
André Cademartori Jacobsen ${ }^{1}$; Helena Beatriz Bettella Cybis ${ }^{2}$; \\ Luis Antonio Lindau; ; André Bresolin Pinto ${ }^{4}$
}

\begin{abstract}
Resumo: Os modelos de geração de viagens, utilizados nos Estudos de Impacto de Tráfego (EIT) de shopping centers, geralmente estimam volumes diários médios anuais de veículos atraídos. Neste artigo são confrontados os volumes estimados por modelos referenciados na literatura com volumes veiculares observados em seis empreendimentos localizados na região metropolitana de Porto Alegre. Quando comparadas com as distribuições de volumes diários de cada shopping center, as estimativas revelam erros expressivos. Modelos baseados apenas na Área Bruta Locável (ABL) mostram-se incapazes de representar as diferenças entre os empreendimentos, indicando a necessidade da incorporação de novas variáveis explicativas. Entende-se que as diferenças entre estimativas e valores observados estejam fortemente associadas ao poder aquisitivo dos clientes. $\mathrm{O}$ artigo propõe modelos não-convencionais de geração de viagens construídos com os dados dos shopping centers estudados. Entre os modelos estimados, o que incorpora a variável "valor do aluguel” das lojas dos empreendimentos resultou nos menores erros de estimativa.
\end{abstract}

\begin{abstract}
Trip generation models, applied in Traffic Impact Studies of shopping centers, usually estimate annual average daily volumes of attracted private vehicles. In this paper we confront volumes estimated by models referred in the literature with observed vehicular volumes of six shopping centers located within the Metropolitan Area of Porto Alegre, Brazil. When compared to the distributions of daily volumes of each shopping center, estimates reveal expressive errors. Models based only on gross leasing areas are unable to represent the differences between the shopping centers, suggesting the need to incorporate new explanatory variables. We understand that the differences between estimated and observed values are strongly associated to the income of the clients. The paper presents non-conventional trip generation models estimated with data from the shopping centers analyzed. Amongst the estimated models, the one that incorporates the variable "rental prices" of the shops resulted in the smaller estimation errors.
\end{abstract}

\section{INTRODUÇÃO}

Shopping centers (SC) são pólos geradores de viagens (PGV) que integram estabelecimentos comerciais e de prestação de serviços em uma única estrutura. Como os usuários de automóvel representam uma parcela significativa dos clientes, as práticas norte-americanas e brasileiras estabelecem que deve haver vagas suficientes nos SC para atender a demanda por estacionamento. A Área Bruta Locável (ABL) destes empreendimentos pode variar entre $160 \mathrm{~m}^{2}$ e $200 \mathrm{mil} \mathrm{m}^{2}$ conforme o Institute of Transportation Engineers (ITE, 2008), apesar da Associação Brasileira de Shopping Centers (ABRASCE, 2010) considerar apenas os que possuem área superior à 5 mil m².

Em diversos municípios, a construção de um PGV

\footnotetext{
${ }^{1}$ André Cademartori Jacobsen, Laboratório de Sistemas de Transportes, Programa de Pós-Graduação em Engenharia de Produção, Universidade Federal do Rio Grande do Sul, Porto Alegre, RS, Brasil. (e-mail: andre.jacobsen@producao.ufrgs.br).

${ }^{2}$ Helena Beatriz Bettella Cybis, Laboratório de Sistemas de Transportes, Programa de Pós-Graduação em Engenharia de Produção, Universidade Federal do Rio Grande do Sul, Porto Alegre, RS, Brasil. (e-mail: helenabc@producao.ufrgs.br).

${ }^{3}$ Luis Antonio Lindau, Laboratório de Sistemas de Transportes, Programa de Pós-Graduação em Engenharia de Produção, Universidade Federal do Rio Grande do Sul, Porto Alegre, RS, Brasil. (email: lindau@producao.ufrgs.br).

${ }^{4}$ André Bresolin Pinto, Matricial Engenharia Consultiva, Porto Alegre, RS, Brasil. (e-mail: andrebresolin@conex.com.br).
}

Manuscrito recebido em 20/1/2010 e aprovado para publicação em 26/2/2010. Este artigo é parte de TRANSPORTES, volume XVIII, número 1, março de 2010. ISSN: 2237-1346 (online). depende de um Estudo de Impacto de Tráfego (EIT) que contemple medidas mitigadoras e compensatórias pelo impacto causado no sistema viário na sua área de influência. Um dos aspectos mais importantes de um EIT é a estimativa do número de viagens atraídas pelos empreendimentos. A grande diversidade de empreendimentos, condições de implantação e perfil de clientes dificulta a definição de modelos genéricos de geração de viagens.

Nos últimos anos ocorreu um crescimento significativo no número e área de SC no Brasil. Entre 2005 e 2010, o crescimento de $21 \%$ no número de SC é ainda excedido pelo aumento nas dimensões, da ordem de 48\%, na Área Bruta Locável (ABL). A explosão de SC nas diversas cidades brasileiras reforça a importância do aperfeiçoamento das metodologias utilizadas. A geração de viagens é um aspecto crítico em um EIT, pois os erros nas estimativas podem levar a prejuízos sociais como, por exemplo, os decorrentes dos congestionamentos viários.

Este artigo apresenta uma análise comparativa entre modelos de geração de viagens de SC referenciados na literatura e modelos estimados a partir de volumes diários de veículos de seis SC situados em Porto Alegre. Neste trabalho foram analisadas séries históricas contemplando períodos superiores a um ano, entre 2005 e 2010. A análise permitiu a caracterização da variação da demanda nos diferentes dias da semana e da variabilidade da demanda nas sextas-feiras e sábados, dias tipicamente considerados em EITs. 
Os modelos de geração de viagens analisados são os de Goldner (1994), CET-SP (2000), Cárdenas (2003), Andrade (2005) e ITE (2008). Jacobsen et al. (2009) apresentam a aplicação desses modelos a quatro SC de Porto Alegre. Este artigo amplia a análise, acrescentados dois novos SC, e propõe modelos de geração de viagens para os SC de Porto Alegre e região metropolitana. Em decorrência de uma análise detalhada das séries históricas, este trabalho ressalta a importância de considerar a variabilidade da demanda nos estudos de geração de viagens e em estudos de impacto de tráfego.

\section{MODELOS DE GERAÇÃO DE VIAGENS PARA SHOPPING CENTERS}

Os modelos de geração de viagem diferem quanto às variáveis explicativas e à amostra utilizada para ajuste dos modelos. O modelo do ITE (2008) baseou-se em um número de SC consideravelmente maior do que os modelos brasileiros, abrangendo um espectro mais amplo de dimensão de empreendimentos localizados em diversas cidades americanas. O modelo da CETSP (2000) foi elaborado para a estimativa de viagens no município de São Paulo, que apresenta uma grande concentração de SC. Por ser a CET-SP o órgão responsável pela avaliação de EIT em São Paulo, este modelo é amplamente difundido. O manual de PGT do DENATRAN (2001) recomenda o uso dos modelos da CET-SP (2000) e Goldner (2004) para geração de viagens por SC.

Os modelos de Goldner (1994), Cárdenas (2003) e
Andrade (2005) foram desenvolvidos a partir de pesquisas acadêmicas. O modelo estimado por Goldner (1994) utilizou uma amostra de âmbito nacional, enquanto Cárdenas (2003) baseou-se em SC situados em cidades de médio porte no interior do estado de São Paulo e Andrade (2005), em SC localizados no município do Rio de Janeiro.

O Quadro 1 apresenta as características dos principais modelos de geração de viagens por automóvel para SC. Para cada modelo são apresentados: a variável explicativa, o tamanho da amostra, algumas características básicas dos SC e as equações dos modelos para sextas-feiras e sábados. Os modelos estimam a variável $\mathrm{V}$, que representa o volume diário médio de veículos atraído pelos SC. As equações do ITE (2008), que originalmente estimam o número de viagens com origem ou destino no SC, foram adaptadas para estimar o volume diário médio de veículos a partir da variável ABL em metros quadrados, conforme os modelos de outros autores.

O ITE (2008) estabelece uma equação para o volume de veículos em dias úteis, e não especificamente para a sexta-feira. A relação entre o volume da sextafeira e a média de todos os dias úteis depende das dimensões do SC. A equação da sexta-feira possui um fator de correção $k$, cujos valores são apresentados no Quadro 1.

À exceção do modelo CET-SP (2000) que usa a Área Computável (ACp), todos os modelos do Quadro 1 usam a Área Bruta Locável (ABL) como variável explicativa. A ABL corresponde à soma de todas as áreas disponíveis para a locação nos SC, exceto quios-

Quadro 1. Características dos modelos de geração de viagens para SC

\begin{tabular}{|c|c|c|c|c|c|}
\hline Modelo & $\begin{array}{c}\text { Variável } \\
\text { explicativa }\end{array}$ & Amostra & Características dos SC & Dia & Equação \\
\hline \multirow[t]{2}{*}{ ITE (2008) } & \multirow[t]{2}{*}{$\operatorname{ABL}\left(\mathrm{m}^{2}\right)$} & \multirow[t]{2}{*}{$\begin{array}{l}302 \text { (sex) } \\
123 \text { (sáb) }\end{array}$} & \multirow[t]{2}{*}{$\begin{array}{l}\text { ABL entre } 1 \text { e } 140 \text { mil m². } \\
\text { ABL média: } \\
\text { - } 30.500 \mathrm{~m}^{2} \text { (sexta) } \\
\text { - } 41.800 \mathrm{~m}^{2} \text { (sábado) }\end{array}$} & sex & $\begin{array}{l}V=8.9472 \cdot \mathrm{ABL}^{0,65} \cdot k \\
R^{2}=0,78 \\
k(A B L<9.300)=1,189 \\
k(9.300<A B L<27.900)=1,087 \\
k(A B L>27.900)=1,154\end{array}$ \\
\hline & & & & sáb & $\begin{array}{l}V=14,614 \cdot A B L^{0,63} \\
\mathrm{R}^{2}=0,82\end{array}$ \\
\hline \multirow{2}{*}{$\begin{array}{l}\text { CET-SP } \\
(2000)\end{array}$} & \multirow{2}{*}{$\mathrm{ACp}\left(\mathrm{m}^{2}\right)$} & \multirow{2}{*}{7} & \multirow{2}{*}{$\begin{array}{l}\text { Não fornece informações } \\
\text { detalhadas }\end{array}$} & sex & $\begin{aligned} V & =0,28 \cdot A C p-1366,12 \\
\mathrm{R}^{2} & =0,99\end{aligned}$ \\
\hline & & & & sáb & $\begin{aligned} V & =0,33 \cdot A C p-2347,55 \\
\mathrm{R}^{2} & =0,99\end{aligned}$ \\
\hline \multirow[b]{2}{*}{$\begin{array}{l}\text { Goldner } \\
\text { (1994) }\end{array}$} & \multirow[b]{2}{*}{$\operatorname{ABL}\left(m^{2}\right)$} & \multirow[b]{2}{*}{15} & \multirow{2}{*}{$\begin{array}{l}\text { ABL entre } 15 \text { e } 62 \mathrm{mil} \mathrm{m}^{2} \text {. } \\
\text { ABL média de } 34.250 \mathrm{~m}^{2} \text {. }\end{array}$} & sex & $V=0,74 \cdot(0,3054 \cdot A B L+1732,7)$ \\
\hline & & & & sáb & $\begin{array}{l}V=0,3054 \cdot A B L+1732,7 \\
\mathrm{R}^{2}=0,89\end{array}$ \\
\hline \multirow{2}{*}{$\begin{array}{l}\text { Andrade } \\
(2005)\end{array}$} & \multirow{2}{*}{$\begin{array}{l}\text { ABL } \\
\left(\mathrm{m}^{2} / 10.000\right)\end{array}$} & \multirow{2}{*}{16} & \multirow{2}{*}{$\begin{array}{l}\text { ABL entre } 6 \text { e } 72 \text { mil m² } \\
\text { ABL média de } 32.700 \mathrm{~m}^{2}\end{array}$} & sex & $\begin{aligned} V & =1091 \cdot e^{0,4063 \cdot A B L} \\
\mathrm{R}^{2} & =0,89\end{aligned}$ \\
\hline & & & & sáb & $\begin{array}{l}V=1347,1 \cdot e^{0,4 \cdot A B L} \\
\mathrm{R}^{2}=0,91\end{array}$ \\
\hline \multirow{2}{*}{$\begin{array}{l}\text { Cárdenas } \\
\text { (2003) }\end{array}$} & \multirow{2}{*}{$\operatorname{ABL}\left(\mathrm{m}^{2}\right)$} & \multirow{2}{*}{6} & \multirow{2}{*}{$\begin{array}{l}\text { ABL entre } 4 \text { e } 27 \mathrm{mil} \mathrm{m}^{2} \\
\text { ABL média de } 17.600 \mathrm{~m}^{2}\end{array}$} & sex & $\begin{aligned} V & =0,2147 \cdot A B L+409,2 \\
\mathrm{R}^{2} & =0,91\end{aligned}$ \\
\hline & & & & sáb & $\begin{array}{l}V=0,273 \cdot A B L+1190,4 \\
\mathrm{R}^{2}=0,86\end{array}$ \\
\hline
\end{tabular}


ques e as áreas comerciais de propriedade de terceiros. Área computável (ACp) definida no modelo do CET (2000) é a área construída total menos área edificada de garagens, área de ático e de caixas d'água.

O modelo proposto por Goldner (1994) apresentado no Quadro 1 é válido para SC com supermercado. A autora não encontrou uma equação satisfatória para o volume de veículos na sexta-feira em SC com supermercado e, neste caso, recomenda a utilização do valor de sábado multiplicado por um fator 0,74.

\section{ESTIMATIVAS DE VOLUMES DE VEÍCULOS PARA SHOPPING CENTERS DE PORTO ALEGRE}

Este trabalho abrange seis SC localizados em Porto Alegre e sua área metropolitana. Este capítulo apresenta as características destes SC, os modelos estimados com base nos volumes observados, e análises comparativas entre a demanda dos SC e os modelos de geração de viagem referenciados na literatura.

\subsection{Características dos shopping centers}

Os SC analisados neste estudo podem ser caracterizados pelos seguintes atributos:

- localizam-se no município de Porto Alegre e sua região metropolitana;

- localizam-se próximos a vias arteriais;

- possuem ABL entre 8 e 37 mil m²

- possuem supermercados;

- possuem cinemas;

- possuem de 15 a $23 \mathrm{~m}^{2}$ de ABL para cada vaga de estacionamento;

- foram construídos entre 1980 e 2005;

- cobram tarifas pelo uso do estacionamento.

Neste artigo são analisados os volumes diários de veículos que ingressam nos SC, registrados nas cancelas dos estacionamentos. Por consequência, são ignorados os automóveis de clientes que estacionam nas vias do entorno. Os dados obtidos são ininterruptos e compreendem períodos superiores a um ano, com exceção dos empreendimentos A (um ano, uma semana por mês) e B (9 meses). Os dados estão concentrados no período entre 2007 e 2008, mas foram considerados também os volumes disponibilizados entre 2005 e 2010.

As características dos SC estudados são apresenta- das no Quadro 2, que relaciona o período analisado, a Área Bruta Locável (ABL), a Área Computável (ACp) e o número de vagas para automóveis nos estacionamentos. $\mathrm{O}$ valor médio do aluguel por metro quadrado nos SC também é indicado no quadro, correspondendo ao valor do aluguel, somados os valores do condomínio e taxa de promoção. Os valores apresentados foram fornecidos por empreendedores ou corretores autorizados.

Observa-se que o número de vagas por ABL varia entre os SC, todos excedendo à Lei Complementar 434/99 do Plano Diretor de Desenvolvimento Urbano Ambiental (PDDUA) de Porto Alegre, que exige um mínimo de uma vaga para cada 25,00 m² de ABL.

\subsection{Modelos desenvolvidos}

Foram realizadas regressões lineares para obter modelos de geração de viagens para esses seis SC de Porto Alegre e sua região metropolitana. Outros estudos que trabalharam com amostras limitadas foram Cárdenas (2003) e CET-SP (2000), que estimaram seus modelos com dados de seis e sete SC, respectivamente.

As primeiras regressões lineares foram realizadas com base na ABL e nos volumes médios de veículos nas sextas-feiras e sábados. Este modelo assume a mesma forma dos modelos de Goldner (1994), CETSP (2000) e Cárdenas (2003), que são lineares e utilizam a mesma variável independente. O modelo $A B L$ resultou em coeficientes de determinação $\left(R^{2}\right)$ 0,75 e 0,70 e nas Equações 1 e 2 para sexta-feira e sábado, respectivamente.

$$
\begin{gathered}
V_{\text {sexta }}=-7,62+0,26 \cdot A B L \\
V_{\text {sábado }}=-11,41+0,33 \cdot A B L
\end{gathered}
$$

em que, $V$ : volume diário médio de veículos;

$A B L$ : área bruta locável $\left(\mathrm{m}^{2}\right)$.

Jacobsen et al. (2009) indicaram que um modelo utilizando somente a variável explicativa ABL dos SC não conseguiria estimar adequadamente o volume médio atraído de veículos, pois a taxa de veículos por $\mathrm{m}^{2}$ de ABL apresentava variações significativas. Entende-se que essa variabilidade esteja provavelmente relacionada a características específicas dos SC, de suas áreas de influência, bem como aspectos socioeconômicos dos clientes.

Quadro 2. Caracterização dos SC estudados

\begin{tabular}{|l|c|c|c|c|c|c|}
\hline & $\boldsymbol{A}$ & $\boldsymbol{B}$ & $\boldsymbol{C}$ & $\boldsymbol{D}$ & $\boldsymbol{E}$ & $\boldsymbol{F}$ \\
\hline Período & jun/07 mai/08 & $\mathrm{abr} / 09 \mathrm{dez} / 09$ & jan/05 set/08 & jan/07 dez/08 & jan/05 jul/06 & jan/07 dez/08 \\
\hline ABL $\left(\mathrm{m}^{2}\right)$ & 36.250 & 27.500 & 24.500 & 8.250 & 31.750 & 31.750 \\
\hline Acp $\left(\mathrm{m}^{2}\right)$ & 86.000 & N/D & 29.000 & 10.000 & 54.500 & 47.000 \\
\hline Vagas & 2.400 & 2.600 & 1.200 & 400 & 1.500 & 1.400 \\
\hline ABL/vaga & 15,1 & 10,6 & 20,4 & 20,6 & 21,2 & 22,7 \\
\hline Aluguel $\left(\mathrm{R} \$ / \mathrm{m}^{2}\right)$ & 420 & 280 & 200 & 250 & 300 & 250 \\
\hline
\end{tabular}


No segundo modelo (modelo $\$ A B L$ ) proposto foram utilizadas as variáveis explicativas ABL e valor médio do aluguel $\left(\mathrm{R} \$ / \mathrm{m}^{2}\right)$ de cada SC. A variável incorporada corresponde a uma proxy para localização, demanda pelo empreendimento e qualidade da infraestrutura oferecida aos clientes. Entre as vantagens no seu uso estão a compatibilidade com os modelos baseados na ABL e a fácil obtenção do seu valor, uma vez que se tenha uma estimativa adequada do valor de mercado do aluguel a ser praticado.

As regressões lineares dos volumes em relação às duas variáveis resultaram nas Equações 3 e 4, com coeficientes de determinação $\left(R^{2}\right)$ 0,92 e 0,83 para sextas-feiras e sábados, respectivamente.

$$
\begin{gathered}
V_{\text {sexta }}=-42,52+0,28 \cdot A B L+19,1 \cdot \$ \\
V_{\text {sábado }}=-51,88+0,25 \cdot A B L+22,1 \cdot \$
\end{gathered}
$$

em que, $V$ : volume diário médio de veículos;

$A B L$ : área bruta locável $\left(\mathrm{m}^{2}\right)$;

\$: valor do aluguel incluindo condomínio e taxas $\left(\mathrm{R} \$ / \mathrm{m}^{2}\right)$;

\subsection{Análise comparativa dos modelos}

O Quadro 3 apresenta o volume diário médio de veículos observados nas sextas-feiras e sábados, a taxa de veículos médios por ABL (Veículos/ABL), e o número de viagens previstas pelos modelos de geração estudados. A relação entre o volume estimado e o observado é indicada pelos percentuais em itálico e permite identificar os casos em que o modelo superestima ou subestima o volume de veículos atraídos. Para facilitar a leitura, os valores apresentados foram arredondados em múltiplos de 50.

A taxa de veículos por ABL reportada no Quadro 3 varia entre os SC, mas percebe-se que A e B apresen- tam taxas maiores que os demais, atingindo valores médios superiores a 0,35 veículos por $\mathrm{m}^{2}$ de $\mathrm{ABL}$ nos sábados. As taxas variam entre 0,16 a 0,29 nas sextasfeiras e entre 0,22 e 0,39 veículos por ABL.

O volume médio de veículos nos sábados é superior ao da sexta-feira, exceto em $\mathrm{D}$, que apresenta volumes semelhantes nos dois dias. Dos modelos apresentados no Quadro 3, apenas o CET-SP não utiliza a $\mathrm{ABL}$ como variável explicativa, sendo que a ausência do valor da área computável (ACp) do SC B impossibilitou a estimativa do seu volume.

A Figura 1 apresenta o comportamento dos modelos de geração que utilizam a ABL como variável explicativa. A análise da figura, que complementa os dados do Quadro 3, permite as seguintes considerações:

- os modelos propostos por Goldner (1994) apresentam as melhores estimativas para volumes de veículos atraídos pelos SC A e B, mas não se ajustam bem aos demais, apresentando estimativas que excedem os volumes observados;

- os modelos propostos pelo ITE (2008) apresentam estimativas superiores às de Goldner (1995) e Cárdenas (2003) para sextas-feiras e intermediárias para sábados, subestimando os volumes de veículos observados em A e B e superestimando os demais;

- os modelos apresentados por CET-SP (2000) superestimam os volumes diários médios, com exceção de $\mathrm{D}$, que possui ABL inferior aos demais empreendimentos;

- os modelos de Cárdenas (2003) apresentam taxas de geração de viagens (veículos por metro quadrado de $\mathrm{ABL}$ ) próximas às de Goldner (1994), com uma redução no intercepto da equação. O modelo de Cárdenas subestima os volumes de veículos de A e B e superestima os

\begin{tabular}{|c|c|c|c|c|c|c|c|c|c|c|c|c|}
\hline & \multicolumn{2}{|c|}{11} & \multicolumn{2}{|c|}{$B$} & \multicolumn{2}{|c|}{$C$} & \multicolumn{2}{|c|}{$D$} & \multicolumn{2}{|c|}{$E$} & \multicolumn{2}{|c|}{$F$} \\
\hline & sexta & sábado & sexta & sábado & sexta & sábado & sexta & sábado & sexta & sábado & sexta & sábado \\
\hline Veí & 0.300 & 200 & 7.850 & .650 & 3.900 & 5.750 & 1.950 & 1.950 & 6.400 & 100 & .300 & 7.600 \\
\hline Veic/t & 8 & & 0,29 & & 6 & & 24 & & 20 & & ,20 & 24 \\
\hline \multirow{2}{*}{$\begin{array}{l}\text { ITE } \\
2008\end{array}$} & 500 & .900 & 7.450 & 150 & .900 & & 3.750 & & .700 & & .700 & .000 \\
\hline & $92 \%$ & $83 \%$ & $95 \%$ & $86 \%$ & $177 \%$ & $48 \%$ & $192 \%$ & $221 \%$ & $136 \%$ & $41 \%$ & $138 \%$ & $132 \%$ \\
\hline \multirow{2}{*}{$\begin{array}{l}\text { CET-SP } \\
2000\end{array}$} & 2.700 & & - & - & .800 & 00 & 1.500 & 1.050 & 13.900 & 550 & 11.900 & 13.300 \\
\hline & $220 \%$ & $7 \%$ & - & - & $174 \%$ & & $77 \%$ & & $217 \%$ & $220 \%$ & $189 \%$ & $175 \%$ \\
\hline \multirow{2}{*}{$\begin{array}{l}\text { Goldner } \\
1994\end{array}$} & 9.500 & 850 & 7.500 & 0.150 & 6.800 & 9.200 & 3.100 & 4.250 & 8.450 & 11.450 & 8.400 & 11.400 \\
\hline & $2 \%$ & $\%$ & $96 \%$ & $5 \%$ & $174 \%$ & $160 \%$ & $159 \%$ & $218 \%$ & $132 \%$ & $161 \%$ & $33 \%$ & $150 \%$ \\
\hline \multirow{2}{*}{$\begin{array}{l}\text { Cárdenas } \\
2003 \\
\end{array}$} & 8.200 & 1.100 & 6.300 & 8.700 & 5.650 & & 2.150 & & 7.200 & & 7.200 & 9.850 \\
\hline & $80 \%$ & $84 \%$ & $80 \%$ & $82 \%$ & $145 \%$ & $137 \%$ & $110 \%$ & $177 \%$ & $113 \%$ & $139 \%$ & $114 \%$ & $130 \%$ \\
\hline \multirow{2}{*}{$\begin{array}{l}\text { Andrade } \\
2005\end{array}$} & 4.800 & 750 & 3.300 & 050 & 2.950 & 3.550 & 1.500 & 1.850 & 3.950 & 4.800 & 3.950 & 4.800 \\
\hline & $47 \%$ & $44 \%$ & $42 \%$ & $38 \%$ & $76 \%$ & $62 \%$ & $77 \%$ & $95 \%$ & $62 \%$ & $68 \%$ & $63 \%$ & $63 \%$ \\
\hline \multirow{2}{*}{$\begin{array}{l}\text { Modelo } \\
\text { ABL }\end{array}$} & 8.550 & 10.850 & 6.300 & 7.950 & 5.550 & 6.950 & 1.350 & 1.550 & 7.400 & 9.350 & 7.400 & 9.350 \\
\hline & $83 \%$ & $82 \%$ & $80 \%$ & & $142 \%$ & & $69 \%$ & & $116 \%$ & & $117 \%$ & $123 \%$ \\
\hline \multirow{2}{*}{$\begin{array}{l}\text { Modelo } \\
\text { \$ABL } \\
\end{array}$} & 10.400 & 3.000 & 6.100 & 7.750 & 4.050 & 5.250 & 2.000 & 2.350 & 7.300 & 9.200 & 6.300 & 8.100 \\
\hline & $101 \%$ & $98 \%$ & $78 \%$ & $73 \%$ & $104 \%$ & $91 \%$ & $103 \%$ & $121 \%$ & $114 \%$ & $130 \%$ & $100 \%$ & $107 \%$ \\
\hline
\end{tabular}

Quadro 3. Volumes médios de veículos observados nos SC e a estimativa dos modelos referenciados na literatura 


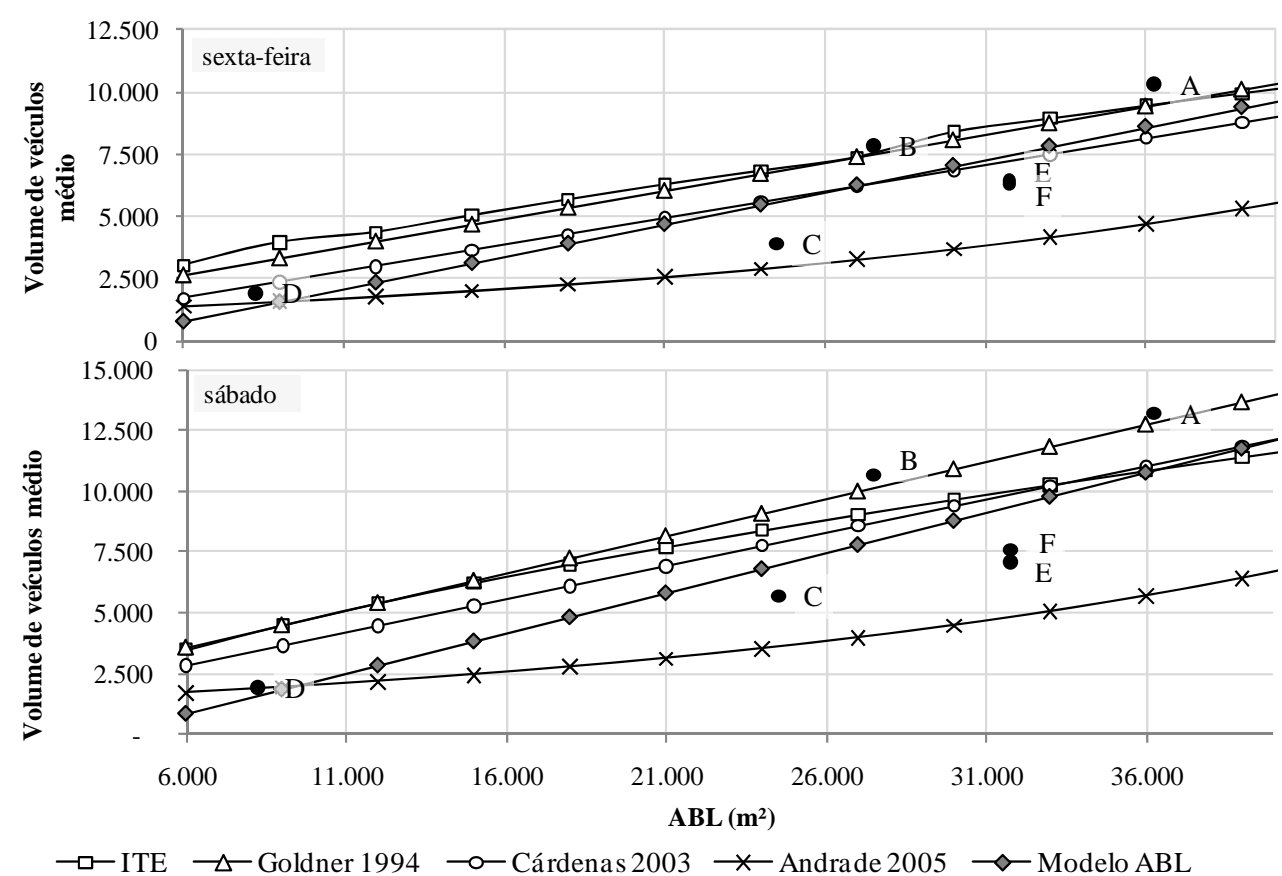

Figura 1. Estimativas do volume médio diário de veículos para sextas-feiras e sábados pelos modelos referenciados na literatura e os volumes observados

volumes dos demais. Este modelo apresenta a melhor estimativa para os volumes das sextasfeiras em D, E e F;

- os modelos de Andrade (2005) subestimam os volumes de todos os empreendimentos, mas apresentam uma previsão de volume aceitável para o sábado em D;

- os modelos ABL, desenvolvidos neste estudo e descritos nas equações 1 e 2 , apresentam melhores estimativas de volume para o conjunto de empreendimentos do que os modelos anteriores, no entanto, os volumes de A, B e D são subestimados, e os de C, E e F superestimados;

- os modelos \$ABL, desenvolvidos neste estudo e descritos nas equações 3 e 4, estimaram volumes para as sextas-feiras e sábados de A, C e F com erros inferiores a $10 \%$ dos valores observados. Os volumes foram subestimados no empreendimento $\mathrm{B}$ e superestimados em $\mathrm{D}$ e $\mathrm{E}$, especialmente nos sábados.

A partir do Quadro 3 e da Figura 1 é possível observar que existem duas categorias de SC. Os empreendimentos A e B apresentam taxas de geração de viagens semelhantes e superiores aos demais. O empreendimentos C, D, E e F, apresentam taxas de geração de viagens menores e relativamente semelhantes. Analisando o contexto de implantação destes empreendimentos é inevitável considerar que a diferença no número de viagens está associada à área de influência do empreendimento, e neste contexto, o poder aquisitivo dos clientes tem um papel importante. Considerando a dificuldade de obter informações confiáveis sobre renda, optou-se por utilizar o valor médio de aluguel por metro quadrado como uma proxy do potencial de vendas das lojas e poder aquisitivo dos clientes.

$\mathrm{O}$ modelo \$ABL, definido pelas equações 3 e 4, e apresentado na Figura 2, é baseado nas variáveis ABL e no valor de aluguel por metro quadrado. Nesta figura, o volume médio de veículos é representado por uma reta para cada valor de aluguel dos SC pesquisados $\left(200,250\right.$, 300 e $\left.420 \mathrm{R} \$ / \mathrm{m}^{2}\right)$. Os SC são representados pela respectiva letra, valor do aluguel e o símbolo correspondente da curva associada. Os erros na estimativa dos volumes, observados na Figura 2 e no Quadro 3, são significativamente inferiores aos dos demais modelos. Este melhor desempenho já era esperado, por resultar de uma regressão dos atributos dos próprios SC, mas a incorporação da variável valor do aluguel resultou em melhoria considerável nas estimativas.

Nos resultados do modelo \$ABL, os maiores erros de estimativa correspondem ao sábado do SC B, que teve o valor subestimado em $27 \%$, e o sábado de $\mathrm{E}$, superestimado em $30 \%$. Erros de estimativa para os demais SC e dias foram inferiores a $25 \%$.

Os parâmetros escolhidos para comparar a precisão das estimativas dos modelos foram os erros absolutos médio e máximo, que são apresentados no Quadro 4. Observa-se que os menores erros foram obtidos com o modelo \$ABL, cujo erro médio foi de $11 \%$ e o máximo de $30 \%$. O erro médio observado no modelo ABL foi superior ao dobro do primeiro modelo. Entre os modelos identificados na literatura, o modelo de Cárdenas (2003) forneceu as melhores estimativas para os SC deste estudo, com erro médio de $28 \%$. Este modelo, entretanto, apresentou um erro máximo de $77 \%$ na 




Figura 2. Estimativa do volume médio diário de veículos para sextas-feiras e sábados pelo modelo $\$ A B L$ e os volumes observados

Quadro 4. Média e valor máximo dos erros absolutos por modelo

\begin{tabular}{|l|c|c|}
\hline \multicolumn{1}{|c|}{ Modelo } & Erro absoluto médio (\%) & Erro absoluto máximo (\%) \\
\hline Modelo \$ABL & $11 \%$ & $30 \%$ \\
\hline Modelo ABL & $24 \%$ & $42 \%$ \\
\hline Cárdenas 2003 & $28 \%$ & $77 \%$ \\
\hline Andrade 2005 & $39 \%$ & $62 \%$ \\
\hline Goldner 1994 & $42 \%$ & $118 \%$ \\
\hline ITE 2008 & $44 \%$ & $121 \%$ \\
\hline CET-SP 2000 & $82 \%$ & $120 \%$ \\
\hline
\end{tabular}

estimativa do volume de sábado do empreendimento D. O modelo com pior desempenho foi o de CET-SP (2000), com erro absoluto médio superior a $80 \%$.

Uma análise semelhante de comparação entre previsões e as condições após a implementação de projetos foi desenvolvida por Muldoon e Blommberg (2008) para pólos geradores de viagens no estado de Oregon (EUA). Os autores estudo relatam erros significativos, que variavam de $19 \%$ a $150 \%$.

\section{ANÁLISE DA VARIABILIDADE DOS VOLUMES DE VEÍCULOS}

Com base nas longas séries históricas disponíveis foi possível desenvolver uma análise da variabilidade. Foram estudadas a variação nos volumes médios diários de veículos ao longo da semana e a variação dos volumes nas sextas-feiras e sábados ao longo de todo período.

\subsection{Variabilidade ao longo da semana}

A análise da demanda ao longo dos diferentes dias da semana demonstrou diferenças significativas entre os SC estudados. A Figura 3 apresenta os volumes mé- dios por dia da semana relativos ao volume médio das sextas-feiras.

Observa-se que, nos diferentes SC, os volumes médios de veículos dos sábados são geralmente superiores ao dos dias úteis, que, por sua vez, são superiores ao de domingo. Os casos extremos são os empreendimentos $\mathrm{C}$, que no sábado possui um volume médio $48 \%$ superior às sextas-feiras e $\mathrm{D}$, cujos volumes de sábado são apenas 1\% superiores. Os SC citados são, casualmente, os que possuem as menores ABL, indicando que possivelmente outros fatores tenham influência maior sobre a variação observada no sábado.

$\mathrm{O}$ domingo geralmente apresenta o menor volume médio de veículos, exceto nos SC B e C, nos quais estes volumes são próximos dos demais dias da semana. Os dias úteis apresentam um comportamento estável, com volumes entre $80 \%$ e $100 \%$ da média das sextasfeiras.

Não é objetivo deste artigo identificar as causas desta variabilidade. Cabe destacar que possivelmente estejam relacionadas a características dos clientes (renda e hábitos de compra), à localização do empreendimento (proximidade a rotas com fluxo de passagem eleva- 


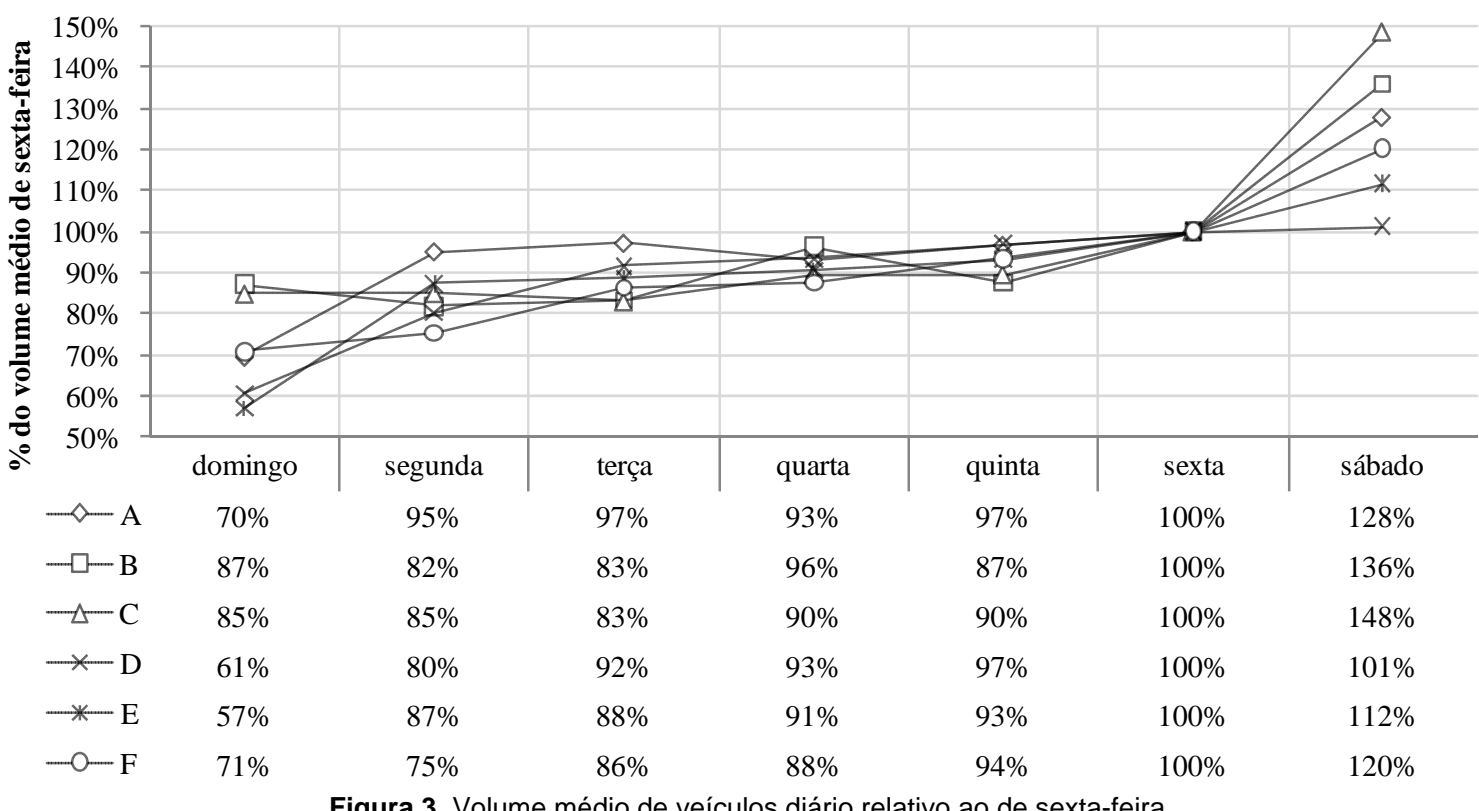

do) e à composição do SC (supermercado, bancos, cinema e restaurantes). Cidades satélite que apresentam deslocamentos pendulares, por exemplo, frequentemente apresentam um volume médio de veículos maior no sábado, quando uma quantidade mais elevada de residentes encontra-se na cidade do que na sexta-feira.

\subsection{Variabilidade entre semanas e as estimativas dos modelos}

A variabilidade anual e mensal do volume de veículos pode ser atribuída a diversos fatores, como os sazonais, proximidade de datas festivas, condições climáticas, além de eventos promovidos pelos SC, como feiras, inaugurações e liquidações. Analisa-se a variabilidade das sextas-feiras e sábados, comparando os volumes observados nas diversas semanas com as médias. Para avaliar se os volumes médios estimados pelos modelos de geração são aproximações razoáveis dos volumes observados, as estimativas são confrontadas com a distribuição de frequências de volumes observados.

A Figura 4 apresenta gráficos da distribuição de frequências relativas acumuladas para cada SC nas sextas-feiras (coluna da esquerda) e sábados (coluna da direita). No eixo das abscissas são apresentados os volumes relativos, com valores entre 40 e $160 \%$ da média do dia. Os volumes observados fora deste intervalo foram ocultados para facilitar a visualização. $\mathrm{O}$ eixo das ordenadas foi posicionado no valor correspondente ao volume médio do dia (100\%), indicando o valor que deveria ser idealmente estimado pelos modelos. As estimativas dos modelos são identificadas por pontos e rótulos nos gráficos.

Observa-se que os volumes dos sábados apresentam maior dispersão em torno da média do que as sextasfeiras. Os SC estudados apresentam comportamentos diferentes. O SC F, por exemplo, apresenta uma dis- persão dos volumes maior do que os outros SC. Por outro lado, esta dispersão é significativamente menor em E.

Analisando as estimativas dos modelos referenciados neste artigo, frente às distribuições acumuladas de volumes para sextas e sábados, é possível identificar mais detalhadamente a extensão das distorções das estimativas. Como situações extremas, destacam-se as estimativas obtidas a partir do modelo de Andrade, que foram excedidas em mais de $90 \%$ dos dias em todos os SC. Destaques de superestimativas de modelos são CET (sábado, SC E), ITE (sábado, SC C) e Goldner (sábado, SC B e F). Nestes casos, os volumes estimados pelos modelos foram superiores praticamente a todos os valores observados. Nos casos nos quais as estimativas dos modelos apresentaram erros superiores a $60 \%$ do volume médio, as informações não foram incluídas nos gráficos.

Os erros de estimativa dos modelos são bastante significativos, e praticamente todos os modelos analisados neste estudo geraram erros absolutos médios superiores a $25 \%$. Segundo as análises reportadas no Quadro 4, erros absolutos médios variam de 11\%, obtido através de um modelo específico para os SC estudados, a $82 \%$, relativo ao modelo de CET-SP. Estudos de impacto baseados em estimativas de demanda com distorções de tal magnitude podem levar a propostas inadequadas, subestimando ou superestimando as obras e ações necessárias para mitigar os impactos da implantação de SC.

A Figura 6 apresenta uma sobreposição das curvas de frequências acumuladas dos SC para sextas-feiras e sábados constantes da Figura 4. Nota-se, a partir da análise da figura, que a maioria dos volumes de veículos observados do ano não apresentam grandes variações em relação à média diária. 



Figura 4. Distribuição de frequências acumuladas dos volumes de veículos observados e as estimativas dos modelos

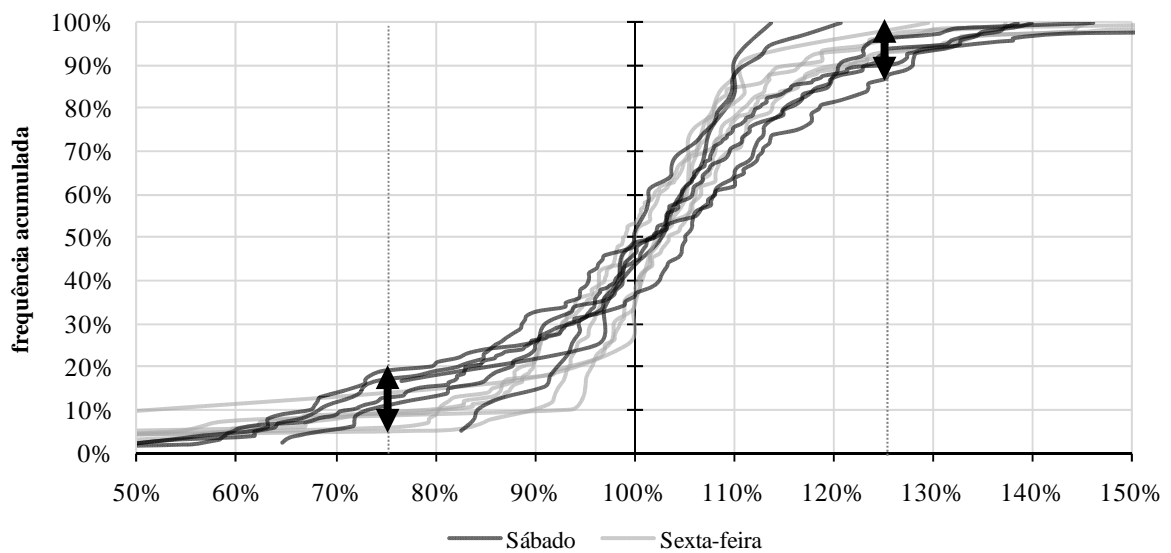

Figura 6. Distribuição de frequências acumulada dos volumes das sextas-feiras e sábados em função do percentual do volume diário médio de veículos

A primeira seta da Figura 6 indica o percentual de

dias cujos volumes observados foram inferiores a $75 \%$ da média diária. Este valor varia entre 5 e $20 \%$ dos di- 
as. O volume estimado por um modelo que subestime a média em $25 \%$, consequentemente, será superado em pelo menos $80 \%$ dos dias, ou nas 42 sextas-feiras ou sábados equivalentes a este percentual.

A segunda seta da Figura 6 indica a o percentual de dias cujos volumes observados foram inferiores a $125 \%$ da média diária. Este volume não é excedido em pelo menos $85 \%$ dos dias. Analogamente, um modelo que superestime a média em $25 \%$ resultará em volumes observados em menos que $15 \%$ dos dias, ou em 8 sextas-feiras ou sábados equivalentes.

$\mathrm{Na}$ eventualidade de um EIT assumir erros nas estimativas dos modelos de geração de viagens correspondentes a $25 \%$ do volume médio, os projetos elaborados para mitigar os impactos no tráfego poderiam ser insuficientes para atender a demanda de mais de 42 sextas-feiras ou sábados por ano, no caso de uma subestimativa. Este número supera as 26 sextas-feiras ou sábados equivalentes à metade dos dias, caso fosse mitigado o impacto correspondente ao volume médio. Por outro lado, estimativas que excedam a média de veículos em $25 \%$, resultariam no superdimensionamento da infraestrutura, compatível com demandas observadas em menos que 8 sextas-feiras ou sábados por ano, ou mesmo nunca observadas.

\section{CONSIDERAÇÕES FINAIS}

A disponibilidade de dados sobre a quantidade de viagens produzidas e atraídas por PGVs é um ponto crítico para a proposição de novos modelos de geração. Vários modelos referenciados na literatura foram desenvolvidos a partir de questionários enviados a administradores de empreendimentos, que por sua vez, informam valores médios e não séries históricas como as utilizadas neste estudo.

Os dados relativos aos SC de Porto Alegre revelam que existem diferenças significativas, mesmo entre empreendimentos de uma mesma região. Entre os seis SC analisados é possível identificar dois grupos. Do primeiro grupo constam dois SC que apresentam taxas de viagens/ABL semelhantes, mas maiores que as dos demais. Analisando o contexto de implantação e composição destes SC é possível assumir que a diferença no número de viagens está associada a características da área de influência do empreendimento e ao poder aquisitivo de seus clientes.

A análise da variabilidade da demanda indicou que, na maioria dos dias, a dispersão em torno da média é pequena. Os volumes observados em $80 \%$ dos dias não apresentaram uma variação maior que $20 \%$ em torno da média, uma consideração importante para o desenvolvimento de EIT.

Nas análises realizadas para SC da região de Porto Alegre, os modelos referenciados na literatura levaram diferenças entre $28 \%$ e $82 \%$. Em casos extremos, as estimativas apontaram para valores inferiores a todos os volumes observados no período. Na situação oposta, foram identificadas estimativas exageradas que superaram $100 \%$ dos volumes observados em alguns SC.

As análises permitem concluir que funções baseadas apenas em variáveis relacionadas à área do empreendimento não produzem estimativas adequadas para os volumes diários médios de veículos atraídos pelos SC. A introdução de outras variáveis explicativas nos modelos de geração de viagens, relacionadas a fatores locacionais e à renda de clientes, poderia melhorar a qualidade dos mesmos, mas a complexidade na caracterização destas variáveis dificulta a sua utilização. Informações sobre renda, por exemplo, são normalmente de qualidade duvidosa e podem requerer pesquisas abrangentes, inclusive com clientes, sujeitas à aprovação e colaboração dos empreendedores.

Neste estudo foi desenvolvido um modelo que utiliza o valor do aluguel como proxy para localização, poder aquisitivo dos clientes, potencial de venda de produtos e serviços ou atributos de qualidade da infraestrutura oferecida. A introdução desta variável, juntamente com a ABL, melhorou a capacidade de explicação do modelo de geração. Apesar dos resultados iniciais promissores, é necessário cautela em relação a utilização do modelo pois, devido às limitações de dados, não foi possível realizar a sua validação.

\section{AGRADECIMENTOS}

Os autores agradecem o apoio financeiro concedido pelo CNPq e CAPES através de bolsas de produtividade de pesquisa e mestrado.

\section{REFERÊNCIAS BIBLIOGRÁFICAS}

ABRASCE (2010) Evolução do Setor. Disponível em: <http://www.portaldoshopping.com.br>. Acesso em: 06 set. 2009.

Andrade, E. P. (2005) Análise de Métodos de Estimativa de Produção de Viagens em Pólos Geradores de Tráfego. Dissertação (Mestrado), 135 p., Programa de Engenharia de Transportes da COPPE-UFRJ, Rio de Janeiro.

Cárdenas, C. B. B. (2003) Geração de Viagens e Demanda por Estacionamento em Shopping Centers do Interior do Estado de São Paulo. Tese (Doutorado), Escola de Engenharia de São Carlos - USP, São Carlos.

CET-SP (2000) Boletim Técnico $n^{\circ} 36$ - Pólos Geradores de Tráfego II. Companhia de Engenharia de Tráfego, São Paulo.

DENATRAN (2001). Manual de Procedimentos para o Tratamento de Pólos Geradores de Tráfego. Departamento Nacional de Trânsito. Brasília.

Goldner, L. G. (1994) Uma metodologia de impactos de shopping centers sobre o sistema viário urbano. Tese (Doutorado), 213 p., Programa de Engenharia de Transportes da COPPE UFRJ, Rio de Janeiro.

ITE (2008) Trip Generation, 8th Edition. Institute of Transport Engineers, Washington D.C.

Jacobsen, A.J, H.B.B. Cybis, L.A. Lindau, A.B. Pinto (2009) Shopping Centers: modelos de geração e variabilidade. XXIII ANPET Congresso de Ensino e Pesquisa em Transportes, Vitória - ES. CD-ROM.

Muldoon, D., L. Bloomberg (2008) Best Practices for Traffic Impact Studies. Transportation Research Record 2077: 32-38." 